\title{
Article \\ Lobatto-Milstein Numerical Method in Application of Uncertainty Investment of Solar Power Projects
}

\author{
Mahmoud A. Eissa ${ }^{1,2, *}$ and Boping Tian ${ }^{1, *}$ \\ 1 Department of Mathematics, Harbin Institute of Technology, Harbin 150001, China \\ 2 Department of Mathematics, Faculty of Science, Menoufia University, Menoufia 32511, Egypt \\ * Correspondence: mahmoud.eisa@science.menofia.edu.eg (M.A.E.); bopingt361147@hit.edu.cn (B.T.)
}

\begin{abstract}
Recently, there has been a growing interest in the production of electricity from renewable energy sources (RES). The RES investment is characterized by uncertainty, which is long-term, costly, depend on feed-in-tariff and support schemes. In this paper, we address the real option valuation (ROV) of a solar power plant investment. The real option framework is investigated. This framework considers the renewable certificate price, furthermore the cost of delay between establishing and operating the solar power plant. The optimal time of launching the project and assess the value of deferred option are discussed. The new three stage numerical methods are constructed, the Lobatto3C-Milstein (L3CM) methods. The numerical methods are integrated with concept of Black-Scholes option pricing theory, and applied in option valuation for solar energy investment with uncertainty. The numerical results of L3CM, finite difference and Monte Carlo methods are compared to show the efficiency of our methods. Our data set refers to the Arab Republic of Egypt.
\end{abstract}

Keywords: stochastic differential equation; numerical simulation; real option; renewable energy; Egypt

\section{Introduction}

A great deal of effort is being put into researching and developing renewable energy (RE) technologies. RE can be generated from wind, solar, biomass, sunlight, tides and flowing water. The primary reason for this effort stems from the environmental impact of using fossil fuels, such as nitrogen and sulfur oxides (NOx and SOx) as well as oil spills similar to the recent major spill in the Gulf of Mexico [1]. In addition, the rising demand for electricity is considered as one of the main reasons that make RE development is also served to increase energy security by reducing reliability on foreign imports of fossil fuels.

Despite the delay with respect to some countries in the world, we can see the U.S. as well as several other regions such as Western Europe, East Asia and North Africa have a massive increase in construction and operation of renewable power production sites. Particularly, we mean the production of electricity from renewable energy sources (RES). In the IEO 2016 [2], long-term global prospects continue to improve for generating electricity from RES. RES are the fastest-growing source of energy for electricity generation, with annual increases averaging $2.9 \%$ from 2012 to 2040.

One of the RES is the solar energy, which can be converted into electricity using photovoltaic (PV) technology [3,4]. Solar is the world's fastest-growing form of RES, with net solar generation, increasing by an average of $8.3 \%$ /year. Solar energy shared 859 billion $\mathrm{kWh}(15 \%)$ of the 5.9 trillion kWh of new renewable generation added over the projection period (See [5]).

The main drivers for fastest-growing of solar, have not only been the economic efficiency and technology breakthroughs in renewable power production, but also been the favorable government support due to environmental concerns. We can see that currently such government interest in support and incentive private investors, but private investors are driven by profit maximization. There are two major groups of schemes which can pave the way for a wider spread: (1) Scheme of tariff based capacity (a payment for KWh of energy generated); (2) Scheme of quota-system (The government 
obliges the heavy industries to use a percentage of its electricity consumption from RES). Wiser et al. [6] addressed some of the government support schemes typically is in the form of subsidies and incentives that are front-loaded in the construction and early operating years in U.S. Furthermore, Faginani et al. [7] discussed the dilemma that arises from certain support schemes is the market risk. Although the market risk factor leading to make optimal use of RES, which implies to limiting the cost to society, but the market risk simultaneously deters investor, thus provides to less RE and higher the price.

In general, the policy instruments aim to keep investors' risks within reasonable limits. In addition, the policies have strongly effect of the price and quantity risks faced by an investor. So, we note that the drivers and investors usually feel major concern in this investment because of uncertain returns. Daim et al. [8], discussed identify of the future adoption, products, and technologies for residential and industrial consumers in a form of a graphical technology road map for wind energy. Snyder et al. [9]. presented the polices are used by European nations to stimulate offshore wind development and discuss the impact of similar policies in the US. Furthermore, the performance of 'market-based' British renewable obligation and German 'feed-in-tariff' systems of RE procurement systems is analysed by Toke [10].

The RE is an uncertain investment such that it is long-term, costly and depend on a feed-in tariff system. The valuation for RE investment must consider the irreversible and flexibility enjoyed by decision makers (i.e, the option to delay investment) in addition to the uncertainty. A. Dixit et al. [11] addressed the subject of traditional valuation techniques based on discounted cash flows inferior to real option analysis under these circumstances. Here, we follow the real option approach (ROA) to address the real option valuation (ROV) of an investment in a Solar Energy (SE) projects and the optimal time to invest under a number of different payment settings [12,13]. Fernandes et al. [14] presented a review of the current state of the art in the application of ROA to investment in non-renewable and RES. Abadie et al. [15] provides a literature review of the real option valuation for the operating wind farm. According to [14,15], this particular literature in the RE sector is still limited. Therefore, attempts to fill this gap would be welcome.

In this work, we consider the ROV of private potential investment in RE under the energy and environmental policies as well as the analysis and assess the impact of uncertainty sources. In other words, the ROV has a crucial dimension ( the option to delay an irreversible investment in RE) under the policies and support schemes, which are provided by drivers; as such it should be embodied in the total value of RE. A real options framework is modeled for use in RE investment using stochastic differential equation (SDEs).

Following this approach, Abadie et al. [15] addressed the value of an operating wind farm and the real option to investment in it under different support schemes. The model considers up to three sources of uncertainty: the electricity price, the wind load, and the certificate (ROC) price. They resorted to a trinomial lattice combined with Monte Carlo simulation, when the analytical solutions are lacking. The authors considered the data refers to UK. Gazheli et al. [16] developed a real option model in order to take into account for uncertainty and irreversibility of the farmer decided to lease agricultural land to a company installing a PV power plant. The uncertainty in agricultural commodity price in addition to the irreversible science it is a 20-year commitment from the farmer are considered. Subsidies introduced by government to increase the investments in the RE sector are discussed. The model is applied to the province in Italy.

Stochastic differential equations (SDEs) are using to model problems in many fields of science [17]. In practice, numerical solutions are becoming increasingly important, because the analytic solutions are usually not available for SDEs. The well-known Euler-Maruyama (EM) method for SDEs was presented with strong convergence order 0.5 in [18]. In order to improve the fundamental analysis of numerical approximations, various implicit numerical methods using split-step techniques have been derived based on Euler method. In 2002, Higham et al. [19] derived the split-step backward Euler (SSBE) method. In addition, the split-step theta (SS $\theta$ ) methods which 
generalize the SSBE method when $\theta=1$ were discussed in [20,21]. Although, these numerical methods are A-stable for linear SDEs, theses methods have strong convergence order 0.5. Using the additional term of the Itô-Taylor expansion, the Milstein method was presented with strong convergence order 1.0 [18]. Based on Milstein method, Wang et al. [22] presented the drifting split-step backward Milstein (DSSBM) method. Guo et al. [23] constructed the modified split-step composite $\theta$-Milstein (MSSCTM) methods. In 2015, Voss et al. [24] combined the predictor-corrector method with a Milstein method to investigate split-step Adams-Moulton Milstein (SSAMM) method. In 2016, the modified split-step theta Milstein (DSS $\theta \mathrm{M}$ ) methods were presented by Tian et al.[25]. Although, these methods improved the convergence order to be 1.0. Unfortunately, we can see that, the mean-square (MS) stability conditions of these split-step methods have some restrict for the parameters and step-size $h$, furthermore, these methods are not A-stable. As far as authors, no implicit split-step numerical methods have strong convergence order 1.0 and A-stable for SDEs..

Numerical methods are needed for real option valuation in cases where analytic solutions are either unavailable or not easily compatible. Approximation of stochastic process for underlying asset can be applied to real option valuation. There are several candidate models for the stochastic evaluation of the underlying asset (see [26]). An overview of two numerical methods available in the context of Black-Scholes-Merton [27,28]. Brennan et al. [29] considered finite difference methods (FDM). Boyle [30] gave the simulation of stochastic process using Monte Carlo (MC) method. The comparative study of FDM and MC method for pricing European option was considered in [31]. In addition, the methods are typically tailored to fit into a specific problem at hand (see $[32,33])$.

It is well known that, when the real option can be modelled using a partial differential equation, then FDM are sometimes applied. Despite the large number of research discussed using FDM for ROV, the FDM has become uncommon used today (particularly amongst practitioners) due to the required mathematical sophistication; these also cannot readily be used for high-dimensional problems [33]. Although the MC method has also developed and is increasing and specially applied to high-dimensional problems, its convergence to the correct values is still slow, which leads to a significant increase in run-time [34]. So recently, there has been increasing interest in deriving new numerical methods, which can possibly avoid shortcomings in the aforementioned methods. In this work, the new classes of split-step numerical methods are constructed, which are A-stable, and convergence with order 1.0. Using Lobatto3C ${ }^{1}$ methods in collusion with Milstein method, the Lobatto3C-Milstein (L3CM) methods are derived. The new numerical methods L3CM methods are applied to valuing the real options, and the results are compared with that of FDM and MC methods.

In this paper, a real option framework is modeled for use in RE investment. The real option framework considers the volatility in RE price during the project lifetime and the development lag between launch the project and start the production ${ }^{2}$. The real option framework differs of a previous work since, the new numerical methods L3CM are integrated with option theory and the four economic elements cost, value, risk and flexibility to value a real option. We examine the new L3CM methods with other commonly used two methods, FDM and MC method in an options valuation for investment with uncertainty in a case study.

The paper is organized as follows. In section 2, we show the development in RE sector. In addition, the investment in generating electricity using solar energy is discussed. The situation of the RE sector in Egypt is provided in Section 3. In Section 4, the L3CM methods are derived to apply in real option framework. A real option framework is designed for use in RE investment in Section

1 The Lobatto3C methods are algebraically stable, B-stable and L-stable. So, the Lobatto3C methods are considered excellent for stiff ordinary differential equations (ODEs) problems [35]

2 Since, the net production revenue cannot be started instantaneously, a time lag has to be allowed between the decision to establish the RE plant and the actual production is the cost of delay (If the cash flows are evenly distributed over time, and the exclusive rights last $\mathrm{n}$ years (20 years), the annual cost of delay can be written as: $\frac{1}{n}=\frac{1}{20}=5 \%$ a year. Though, this cost of delay rises each year, to $\frac{1}{19}$ in year $2, \frac{1}{18}$ in year 3 and so on, making the cost of delaying exercise larger over time). 
5. In Section 6, A case study of the solar thermal in Egypt is introduced. Furthermore, Comparison between the L3CM, FDM and MC methods is presented to explain the efficiency of the new numerical methods.

\section{Renewable Energy Investment}

As long as other concerns like the rising demand of electricity and the risks of climate change increases the importance of RES. In fact, RES are becoming ever more relevant in the generation of electricity. RES account for a rising share of the world's total electricity supply, and they are the fastest growing source of electricity generation in the IEO 2016 [5] (See Figure 1). Total generation from RES increase by $2.9 \%$ /year, the renewable share of world electricity generation grows from $22 \%$ in 2012 to $29 \%$ in 2040 . The generation of electricity from solar is increasing by an average of $8.3 \% /$ year. Of the 5.9 trillion $\mathrm{kWh}$ of new renewable generation added over the projection period, solar energy for 859 billion kWh 15

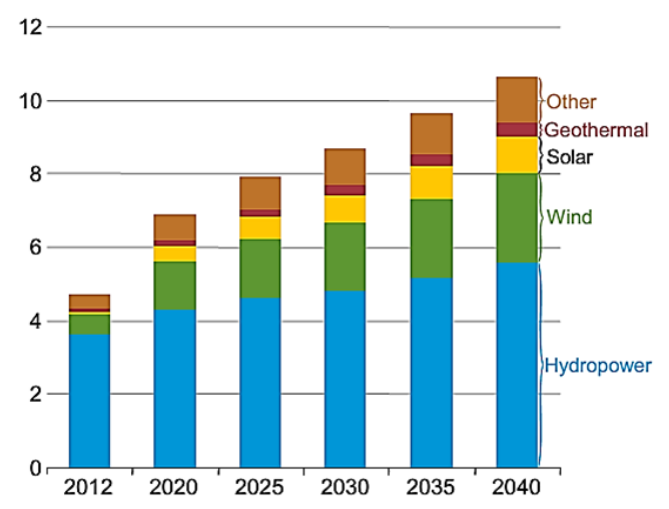

Figure 1. World net electricity generation from renewable power by fuel trillion KWh [36]

A great deal of effort is being put into researching and developing renewable energy technologies. Bloomberg New Energy Finance tracks deals across the financing continuum, from $R \& D$ funding and venture capital for technology and early-stage companies, through to the asset fiance of utility-scale generation projects [36] (See Figure 2).

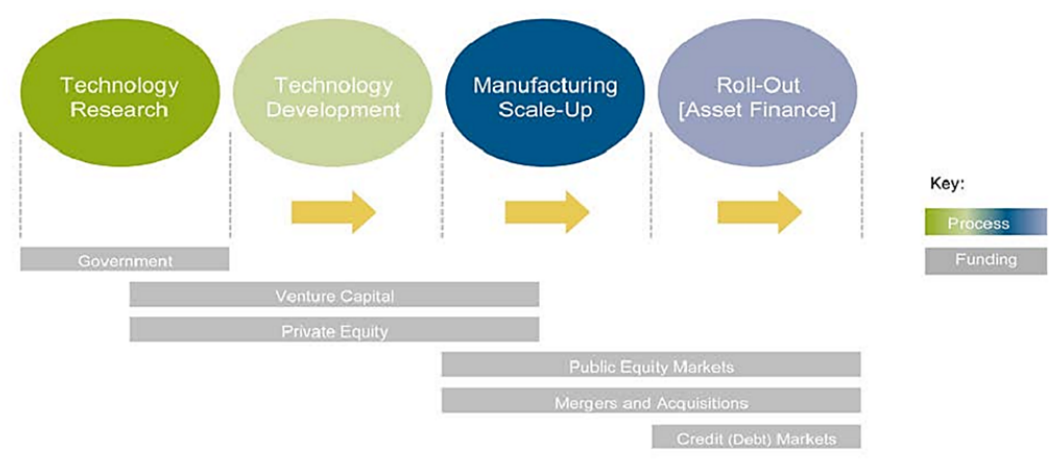

Figure 2. Bloomberg New Energy Finance tracks [36]

RE sets new records in 2015. Investments reached nearly $\$ 286$ billion six times more than in 2004. For the first time, more than half of all added power generation capacity came from RES. All this happened in a year, which prices of fossil fuel commodities-oil, coal and gas-plummeted. So far, the drivers of investment in RE, including climate change policies and improving cost-competitiveness, have been more than sufficient to enable RE to keep growing their share of world electricity generation. Figure 3 (Left) shows that, investment in RE rise $5 \%$ to $\$ 285.9$ billion, taking it above the 
previous record of $\$ 278.5$ billion reached in 2011, and that investment in RE has been running at more than $\$ 200$ billion per year for six years now. The stand-out contribution to the rise in investment to a new record came from China, which lifted its outlays by $17 \%$ to $\$ 102.9$ billion, some $36 \%$ of the global total. Investment also increased in the US, up $19 \%$ at \$ 44.1 billion; in the Middle East and Africa, up $58 \%$ at $\$ 12.5$ billion, and in India, up $22 \%$ at \$ 10.2 billion.

Investment in solar has achieved the highest growth in 2015 between RES. Solar saw a $12 \%$ increase to $\$ 161$ billion, and wind a $4 \%$ boost to $\$ 109.6$ billion. Biomass and waste-to-energy suffered a $42 \%$ fall to $\$ 6$ billion; small hydro projects of less than $50 \mathrm{MW}$ a $29 \%$ decline to $\$ 3.9$ billion; biofuels a $35 \%$ drop to $\$ 3.1$ billion; geothermal a $23 \%$ setback to $\$ 2$ billion; and marine (wave and tidal) a 42 $\%$ slip to just $\$ 215$ million. Figure 3 (Right) shows the sector split for global investment.
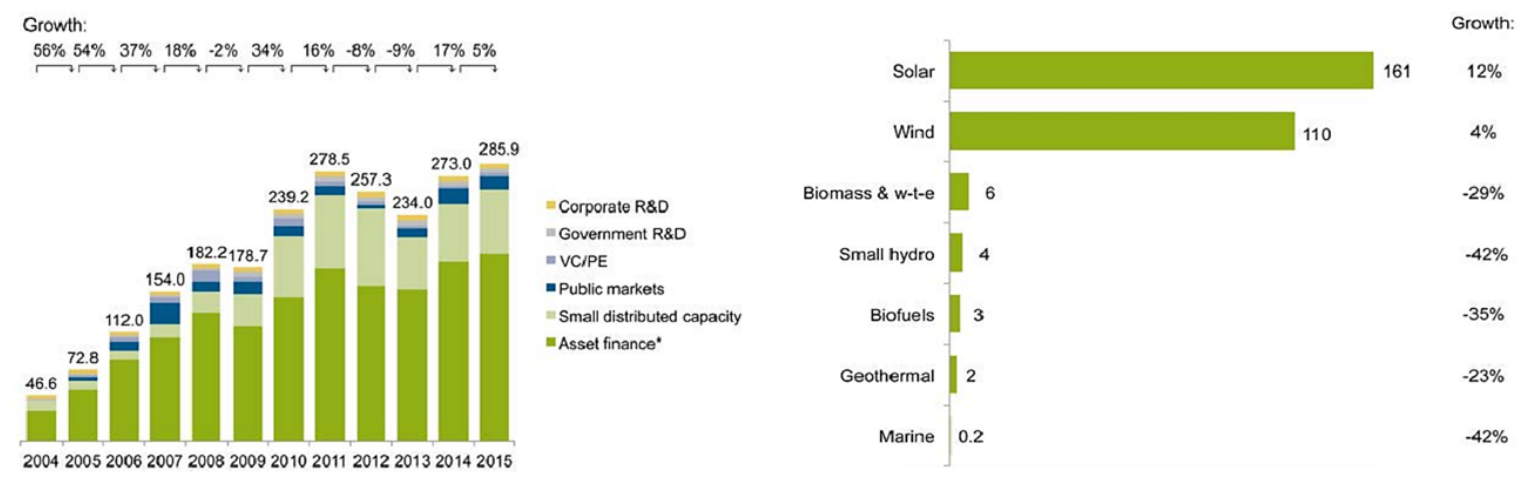

Figure 3. Real MS-stability regions: (a) Global new investment in RE by asset class. (b) Global new investment in RE by sectors, 2015, and growth in 2014. \$BN [36]

In order to pave the way for a wider spread of investing in renewable energy, a number of public support schemes have been considered. These schemes can be divided in two major groups:

- Regulatory price-based mechanisms (a payment for kWh of energy produced).

- Regulatory quantity-based mechanisms (the government sets a desired level of RES and 'green' generators receive tradable certificates according to their production).

Fagiani et al. [7] point out, a dilemma arises here: market risk provides an incentive to make efficient use of resources, thus limiting the cost to society, but it simultaneously deters investors, thus potentially resulting in less RE and higher prices (as they include a higher risk premium). Regarding the support schemes, the literature has argued, especially in recent times, that a key driver of RE investment is keeping investors risks within reasonable limits. Three particular risk factors can stem from the policy instruments themselves:

- The type of instrument (e.g., feed-in tariffs, tradable green certificates);

- Constantly changing support schemes;

- The design details of the particular instrument.

Policy characteristics strongly affect the price risk and the quantity risk faced by an investor. However, their scope in mitigating other sources of technical risk [37,38] and financial risk [39] is more limited. Uncertain returns on these investments are generally considered a major cause for concern for developers and investors alike.

It was stated earlier that, when valuing renewable energy projects, there is uncertainty stemming from long-term, costly, depend on a feed-in tariff system, and random behavior of prices associated with the energy source itself. When considering solar as a RES, one of the sources of uncertainty is future solar power as well as future electricity prices. When a storage system is considered the uncertainty remains the same; although the storage system is in place to make the energy source more predictable, there is still uncertainty in how much solar power we will see at a given hour, as 
well as uncertainty in the price of electricity at a given hour. We can use real options in this setting to determine the optimal time of launching the project and assess the value of real options.

\section{Renewable Energy Sector in Egypt}

In this section, an overview of the RE sector in Egypt is provided. Furthermore, we show the support schemes, which are introduced by government to increase investment opportunities in generating electricity using Solar power. In 2008, the government announced the strategic plan to reach $20 \%$ of the total electricity generated from RE by 2020 Vs $9.1 \%$ in 2013 . The country enjoys a total annual global solar irradiance of up to $2.6 \mathrm{TWh} / \mathrm{m}^{2}$ and a total annual sunshine duration of up to 4,000 hours yearly [40]. The World Bank acknowledged Egypt's solar power advantage. It explains that, there are many best areas for solar energy. Figure 4 shows the potential of solar energy in Egypt.

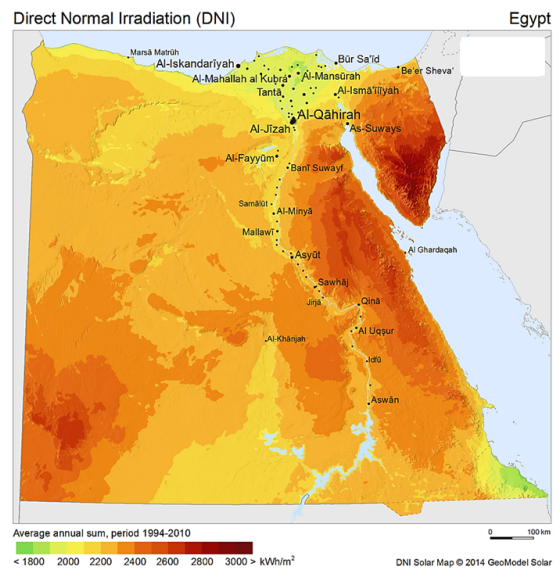

Figure 4. Potential of solar and wind energy in Egypt (Source: Solar gis http:/ / solargis.info)

Fossil fuels have shared $91 \%$ of electricity generation, in addition $9 \%$ from RES. Of $9 \%$ RE generation there are $7.7 \%$ hydro-power, $1.2 \%$ wind, and $0.1 \%$ solar [41]. In recent years, the Egyptian Electricity Holding Company (EEHC) has faced a gap on the power supply side, which caused recurring power cuts from 2012 to 2015. This gap will increase if the lack of investment in energy generation, both conventional and renewable continued.

The Egyptian government has adopted an ambitious plan to reach $20 \%$ of the total electricity generated from RE by 2020 including $2 \%$ solar. The target is expected to be met by reaching the solar energy target of 3500 MW installed capacities up to 2027 [41] Vs the total capacity of 140 MW in 2014 [42]. The Egyptian government has introduced the following policies to foster the increasing of RE energy contribution

\section{Public Competitive Bidding}

Issuing tenders internationally requesting private sector to supply power from RE projects.

2. Third party access (TPA)

Investors are allowed to build and operate RE power plants to satisfy their electricity needs or to sell electricity to other consumers though the national grid.

3. Feed in Tariff (FIT)

In September 2014, the government passed the key Feed-In Tariff Law (The feed-in tariff enacted by decree 1947/2014 [43,44]), triggering wide interest from international developers and investors. The main parameters of the Feed-In Tariffs are:

- Solar power stations: The value of the tariff is divided into five scales according to the production capacity of the station and the value of the tariff will be fixed during the contract period which reaches 25 years. 
- Land allocation: Through the use of craft scheme for a period of time equal to the contract period. Also, the land will be given with just $2 \%$ of the total power generated revenue from the plant. As well as, the customs will be $2 \%$ of the total items cost.

- Electricity: Produced through renewable energy stations has priority access to the electricity grid.

- Government support and guarantee: For power stations that exceed $500 \mathrm{KW}$, include low-interest credit facilities.

\section{Net Metering}

In January 2013, EgyptERA adopted a net-metering policy that allows small-scale renewable energy projects to feed on electricity to the grid. Generated surplus electricity will be discounted from the balance through the net-metering process.

\section{Quota system}

Heavy industries, consumption will be obliged to use a percentage of its electricity consumption from RE sources.

One of the challenges is facing the Egyptian government to implement RE strategy is that, the solar power plant investment is irreversible and uncertain. The solar energy projects are long-term, costly, depend on a feed-in tariff system. The real option framework, which takes into account investment irreversibility, uncertainty and flexibility in RE investment was addressed in [11,16,45]. In the following, we derive new classes of numerical methods, the L3CM methods for SDEs. We discuss the applicability of the L3CM methods to approximate a stochastic process arising from real options analysis for the underlying asset in assessing the uncertainty investment.

\section{The Lobatto3C-Milstein method for SDEs}

Numerical methods are needed for real option valuation in cases, where analytic solutions are either unavailable or not easily compatible. In this work, we construct L3CM as a new numerical methods, which can be used to approximate the stochastic process for the underlying asset in real option valuation. We consider the Itô SDEs of the form

$$
\mathrm{d} y(t)=f(y(t)) \mathrm{d} t+g(y(t)) \mathrm{d} W(t), \quad y\left(t_{0}\right)=y_{0}, \quad t \in\left[t_{0}, T\right],
$$

where $f(y(t))$ is the drift coefficient, $g(y(t))$ is the diffusion coefficient and wiener process $W(t)$ is defined on a given probability space $(\Omega, \mathcal{F}, P)$ with a filtration $\left\{\mathcal{F}_{t}\right\}_{t \geq 0}$ satisfied the usual conditions, whose increment $\Delta W(t)=W(t+\Delta t)-W(t)$ is a Gaussian random variable $N(0, \Delta t)$.

Recently, there are several attempts to construct numerical methods based on split-step techniques, to improve the fundamental analysis contains convergence and stability of numerical solutions for SDEs. It is well known that, there are many A-stable split-step numerical methods with convergence order 0.5 for scalar linear SDEs, such as SSBE and SS $\theta$ methods. The split-step numerical methods with convergence order 1.0 are constructed for SDEs, for example the DSSBM method and SSAMM method. Unfortunately, we can see that the MS stability conditions of these methods for linear SDEs have some restrict for the parameters and step-size h. Furthermore, Figure 5 shows these methods are not A-stable. 


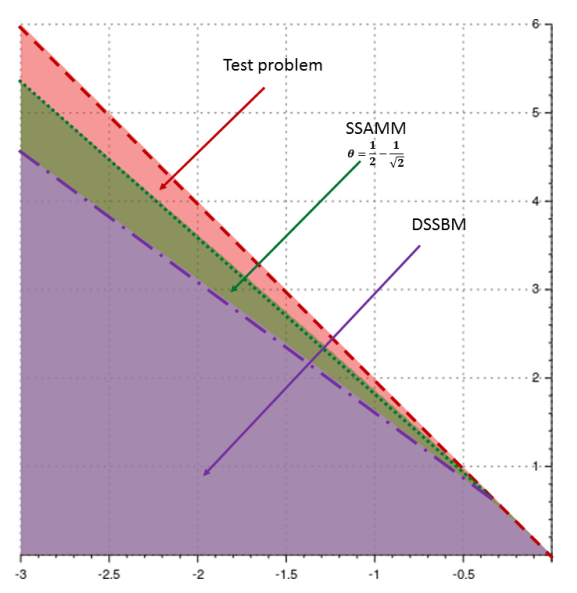

Figure 5. Real MS-stability regions of DSSBM, SSAMM, and test problem

In the following, in order to improve the numerical stability properties, the Lobatto3C-Milstein (L3CM) methods are derived for SDEs (1). The Lobatto3C ${ }^{3}$ methods have the following form (The basic information about lobatto3 $\mathrm{C}$ methods is presented in Appendix A).

$$
\begin{aligned}
Y_{n i} & =y_{n}+h \sum_{j=1}^{s} a_{i j} f\left(t_{n}+c_{j} h, Y_{n j}\right), \quad i=1,2, \ldots, s, \\
y_{n+1} & =y_{n}+h \sum_{j=1}^{s} b_{j} f\left(t_{n}+c_{j} h, Y_{n j}\right)
\end{aligned}
$$

Now, using the Lobatto3C formula (2-3) in collusion with Milstein method, we derive the L3CM methods for SDEs (1) as follows

$$
\begin{aligned}
\tilde{Y}_{n i} & =y_{n}+h \sum_{j=1}^{s} a_{i j} f\left(\tilde{Y}_{n j}\right), \quad i=1,2, \ldots, s, \\
\hat{y}_{n} & =y_{n}+h \sum_{j=1}^{s} b_{j} f\left(\tilde{Y}_{n j}\right), \\
y_{n+1} & =\hat{y}_{n}+g\left(\hat{y}_{n}\right) \Delta W_{n}+\frac{1}{2} g^{\prime}\left(\hat{y}_{n}\right) g\left(\hat{y}_{n}\right)\left[\left(\Delta W_{n}\right)^{2}-h\right],
\end{aligned}
$$

where $y_{n}$ is approximation to $X\left(t_{n}\right), s \geq 2$ is the stage value, the coefficients $a_{i j}, b_{j}$ characterized the L3CM methods, with increments $\Delta W_{n}:=W\left(t_{n+1}\right)-W\left(t_{n}\right)$ are independent $N(0, h)$-distributed Gaussian random variables and $y(0)=y_{0}$. Moreover, $y_{n}$ is $\left\{\mathcal{F}_{t_{n}}\right\}$-measurable at the mesh-point $t_{n}$. It is well known that, the two implicit equations need to be solved for $\tilde{Y}_{n i}, i=1, \ldots, s$ and $\hat{y}_{n}$.

Eissa et al. [46] provided that the L3C2M method (i.e. $s=2$ in (4-5)) is converge strongly with order 1.0 under Lipshitz condition and linear growth condition. Furthermore, the mean-square (MS) stability of L3C2M method is investigated for SDEs with both real and complex parameters. It is shown that the L3C2M method preserves the MS-stability of the exact solutions under no restriction on the step-size in the mean-square sense. In addition, the method is A-stable. In the following, the new L3C2M method (4-6) will be applied in the geometric Brownian motion (GBM), which is used to model of ROV (Note that, this geometric Brownian motion (GBM) is especial case of SDEs (1)).

3 Note that, the Lobatto3C methods are L-stable (strong stability) and have been used successfully in solving stiff initial value ODEs systems [35]. 


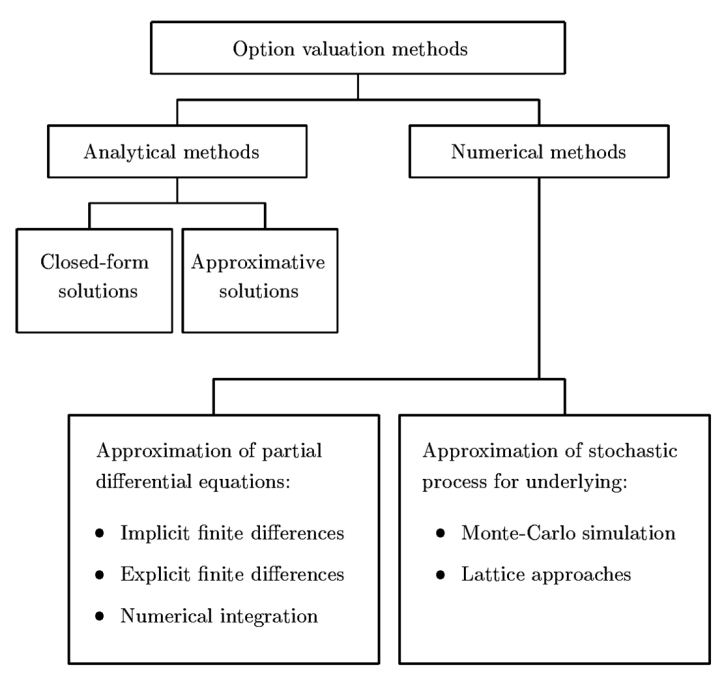

Figure 6. Classification of ROV methods

\section{The Real Option Framework}

The valuation of real option plays an important role in the real option planning. The framework for real option provides an especial viewpoint in valuing investment with uncertainty. There are many different methods can be applied to an ROV, these methods can be categorized into analytical and numerical methods. They can be further divided into subsections as represented in Figure 6. M. Schulmerich [47] gave an overview, in-depth discussion and mathematical descriptions of some specific methods. The ROV process can be divided into five steps as follows [48]:

1. Finding uncertainty investment opportunity.

2. The probability distribution of the uncertainties is approximated.

3. Know and analyze available real options.

4. Real option valuation.

5. Develop real options mind-set: by comparing the value of the options and the cost to obtain options, a set of strategies and decisions can be reached. Meanwhile, the mind-set regarding flexibility available and different is established.

In this section, we consider the solar plant power as an uncertainty investment opportunity. We develop a model to assess the value of deferred option. At any stage of the project, the model can inform a strategic option to defer the project. Based on the particular characteristics of real option in RE investment, a deferred option of solar power plant is considered, where the cash flows are uncertain. We assume that the revenues will start the operation time of the solar power plant (i.e. we consider the cost of delay (Time lag between the decision to establish and the actual production).

In this real option framework, we distinguish the numerical methods of the ROV. We examine the applicability of the $\mathrm{L} 3 \mathrm{C} 2 \mathrm{M}$ method of ROV and compare the results with that of the FDM and MC method. The L3C2M method is integrated with option theory and the four economic elements cost, value, risk, and flexibility to value the real option. The real option framework considers the volatility in solar energy price during the project lifetime, and the development lags between launch the project and start the production. The decision maker is facing an uncertain utility stream for investment. The valuation of real options helps the decision maker to evaluate the investment opportunity.

\subsection{Frame Work Application}

With the solar energy investment, the solar energy is the underlying asset. The value of the asset is based upon two variables, the estimated of the installed Capacity (MW) of the solar energy power 
plant and the pricing system. To value a solar energy investment as a real option, we need to make assumptions about a number of variables as follows

\section{Availability of the solar energy source:}

At the outset, since this is not known with certainty, the availability of renewable has to be estimated. The investor can estimate the installed capacity (MW) of the solar energy plant and produced energy $(\mathrm{kWh})$ by environmental assessment studies.

2. Estimated cost of establish the solar energy plant:

The estimated development cost is the exercise price of the option. The cost of establishing the solar energy plant can be estimated by feasibility studies for the projects.

3. Time to expiration of the option:

The life of a RE option can be defined as a contract period, that period will be the lifetime of the option. For example, the contract in the sector of RE is long-term contract approximately from 20 to 25 years.

4. Variance in value of the cash flows:

The variance in the value of the cash flows is determined by two factors, variability in the pricing system of the RE, and variability in the estimate of the availability of the RE. In the more realistic case where the average of the RE resources and the RE price can change over time, the option becomes more difficult to value.

\section{Cost of Delay:}

Since, the net production revenue cannot be started instantaneously, a time lag has to be allowed between the decision to establish the solar energy plant and the actual production is the cost of delay ${ }^{4}$.

\subsection{Stochastic Model}

In this model, the L3C2M numerical method is examined. GBM is used to model the ROV. Suppose that, we are seeking a valuation to a project with a finite lifetime $t \in[0, T]$. The cash flows $S$ from the investment are stochastic with a standard deviation $\sigma$ and risk-free interest rate $r$. Hence, the evolution of cash flows over time are described as

$$
\mathrm{d} S(t)=r S(t) \mathrm{d} t+\sigma S(t) \mathrm{d} W(t), \quad t \in[0, T] .
$$

In the following, we derive a valuation for the investment case study problem (7) using the L3C2M numerical method. The SDEs (7) describes the paths of cash flows for the lifetime of solar power plant $t \in[0, T]$. The path values of $S(t)$ can be calculated iteratively by L3C2M method, which is introduced in the previous section. The future steps depend on the type of real option.

\section{The deferred option}

If we assume that, a project requires an initial up-front investment of $I$ (Initial cost), and that the present value of expected cash inflows computed right at time $T$ is $S(T)$. The value of the defer option at time $T$ is denoted by $V(S, T)$ as follows

$$
V(S, T)=e^{-r T} E[\max (S(T)-I, 0)] .
$$

The value of the real option can be determined by calculating the expected value in (8) for a given $n$ paths, as an approximation to the expected value. The value of $S(t)$ can be determined using L3C2M method for each path. Finally, we compare the value of real options (8) with the value of real options which are computed by FDM and MC method to show the efficiency of our method L3C2M.

4 If the cash flows are evenly distributed over time, and the exclusive rights last $\mathrm{n}$ years (20 years), the annual cost of delay can be written as: $\frac{1}{n}=\frac{1}{20}=5 \%$ a year. Though, this cost of delay rises each year, to $\frac{1}{19}$ in year $2, \frac{1}{18}$ in year 3 and so on, making the cost of delaying exercise larger over time 


\section{A Case Study : 140 MW Solar Power Plant in Kuraymat, Egypt}

In this section, we present numerical solutions for an actual case study of the solar power plant project in Egypt and analyze the numerical results. We test the evaluation model for deferred option using L3C2M numerical method. We demonstrate the efficiency of numerical method on real options framework by comparing with FDM and MC method.

Our data below are for the solar combined cycle power plant in Kuraymat, Egypt, estimates of key parameters. They are relevant for computing revenues and initial cost over the useful life-time. Through detailed information was published in the annual report of New and Renewable Energy Authority (NREA) 2012/2013 [42], we could get and estimate the following information about the project

- The installed capacity is $C=140 \mathrm{MW}$, including solar share of $20 \mathrm{MW}$ (Think of the total area of the integrated solar field is about $644,000 \mathrm{~m}^{2}$ and the total solar collector is about 1920 solar collector containing 53760 mirrors)(NREA nnual report 2012/2013 [42]).

- The total cost is about $I=340$ \$ Million, and the development lag is 4 years (NREA nnual report 2012/2013 [42]).

- The life-time of the project $T=25$ years. (The feed-in tariff enacted by decree $1947 / 2014[43,44]$ ).

- The tariff applied to the electricity generated from solar were $P=0.1434 \$ / k W h$ (The feed-in tariff enacted by decree $1947 / 2014[43,44])$

- The risk-free interest rate considered is $r=8.75 \%$, which corresponds to the 10-years Egypt government debt in September 2014 (Source: Egypt Central Bank [49]).

In the following, we will estimate the discount cash-flow and the variance of the purchase price of electricity from solar power plants.

\subsection{Estimate Discount Cash-Flows}

The feed-in-tariff is generally claimed to be the most effective method for promoting RE. Let $P$ denote the fixed tariff applied to the electricity generated from the solar power plant. According to $[43,44]$, the feed-in-tariff was enacted in October 2014 and provides for a sophisticated pricing system, differentiating between solar projects as well as project installed capacity. The key of the pricing system is indicated, which are relevant to international investors are

- $500 \mathrm{KW}$ up to $20 \mathrm{MW}: 0.136$ \$.

- $20 \mathrm{MW}$ up to 50MW: $0.1434 \$$.

The capacity of the project is $C=140 \mathrm{MW}$, including solar share of $20 \mathrm{MW}$. So, the feed-in-tariff is considered to be $P=0.1434 \$ / \mathrm{kWh}$. Using the total produced energy (GWh) in a given year in Table 1 [42,50], The average of producing energy ( $\mathrm{kWh} /$ yaer) is estimated $S_{y}=305 \cdot 10^{6} \mathrm{kWh} /$ year.

Table 1. The total produced energy (GWh) per year

\begin{tabular}{|c|c|c|c|}
\hline $2010 / 2011$ & $2011 / 2012$ & $2012 / 2013$ & Average \\
\hline 206 & 479 & 230 & 305 \\
\hline
\end{tabular}

The discount cash flow $C F$, in U.S. Million Dollar, of the investment under this scheme, which consider development lag is [51]

$$
C F=S_{0}=\frac{0.1434 \cdot 305 \cdot 10^{6} \cdot 25}{(1.9)^{2}}=302.8878
$$

\subsection{Estimate the Volatility}

In July 2014, the Egyptian government issued its decree 1257/2014, which determines the increase of electricity future price gradually over 5 years from 2014-2019 [52]. This decision was taken 
within the Egyptian government plan to reduce the energy support. In October 2014, the Egyptian government issued, the feed-in tariff enacted by decree 1947/2014 [43,44], which determines the purchase price of electrical energy supplied to the Egyptian company to transport electricity, from the plants produce electricity of RES. Furthermore, reconsidering this price after two years from the date of publication of the decree, commensurate with the change in the selling price of electricity for the user.

Using electricity selling prices stated in the decree 1257/2014 [52], and following [15], we can derive the regression model whose residuals allows us to compute the volatility:

$$
\sigma=0.1045
$$

In the following Table 2, we summarised all of data sources for the case study

Table 2. Parameters used in the investment option case

\begin{tabular}{|c|c|c|c|c|}
\hline Parameter & Symbol & Value & Unit & Source \\
\hline Current CF from investment & $S_{0}$ & 302.8878 & \$ US Million & Subsection 6.1 \\
Fixed investment cost & $I$ & 340 & \$ US Million & NREA nnual report 2012/2013 [42] \\
Time to invest & $T$ & 25 & Years & Feed-in tariff decree 1947/2014 [43,44] \\
S.d. of cash flows & $\sigma$ & 0.1045 & & Subsection 6.2 \\
Risk-free discount rate & $r$ & 0.0875 & & Egypt Central Bank [49] \\
\hline
\end{tabular}

\subsection{Valuation the Deferred Option}

We consider the inputs in Table 2 to discuss the deferred option model as follows. We use the closed-form solution to benchmark the numerical results. A close resemblance to the pricing of an European call option ${ }^{5}$ with the Black-Scholes equation [27]. Plugging the given parameters into the closed-form Black-Scholes equation yields

$$
V_{\text {exact }}=264.7410 \text {. }
$$

\section{L3C2M method}

We derive a numerical solution with the L3C2M method for the investment option. In addition to the parameters listed in the Table 2, we have additional parameter $\theta=0.8, h=0.145$ such that the sample size is $N=T / h$ and we compute 5000 different discredited Brownian paths over lifetime $(M=5000)$. We get from (8)

$$
V_{L 3 C 2 M}=264.7611
$$

If we compare the value of method with the exact solution, we find that the value of method is very close to the exact solution. Moreover, note that the investment is valuated naturally in the whole domain with both methods. Comparing the option values, we note that the error in both methods is approximately the same and decreases rapidly as the length of the time steps. Figure 7 shows the mean-square error at time $T$ versus the step-size $h$ is analyzed in log-log diagram.

\section{Monte Carlo simulation}

5 In finance, a European option can be exercised only at the expiration time of the option, while an American option can be exercised at any point of time during the option lifetime. Given the price of underlying security $P$ and the strike price $S$, the payoff for a call option is defined as $\max (P-S, 0)$ and for a put option as $\max (S-P, 0)$. 


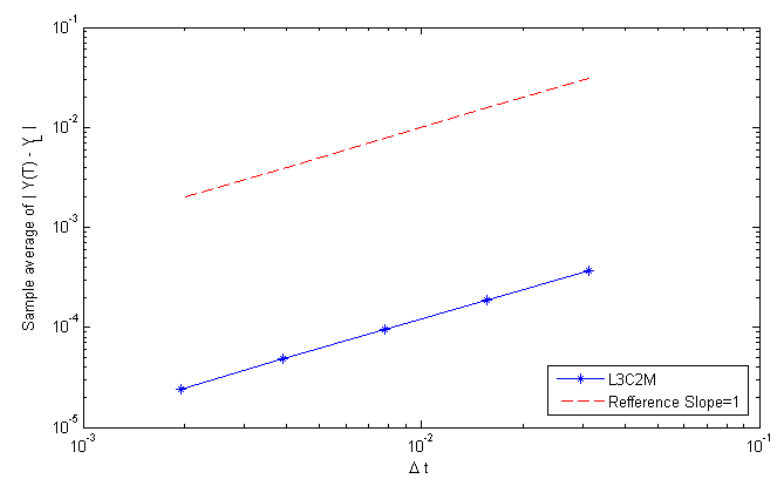

Figure 7. The MS error for the L3C2M method.

Following [9], we run the MC simulation with the parameters given in Table 2. Using a sample size of $n_{\max }=1.5 \cdot 10^{6}$ and $95 \%$ confidence level, the simulation yields the value of investment option:

$$
V_{M C}=264.8050 \pm 0.3161
$$

We note that the value is reasonably close to the exact value. To investigate the convergence properties we run the simulation with smaller sample sizes, descending evenly to $n_{\min }=5 \cdot 10^{4}$. The results of the simulation are presented in Figure 8 along with the $95 \%$ confidence level.

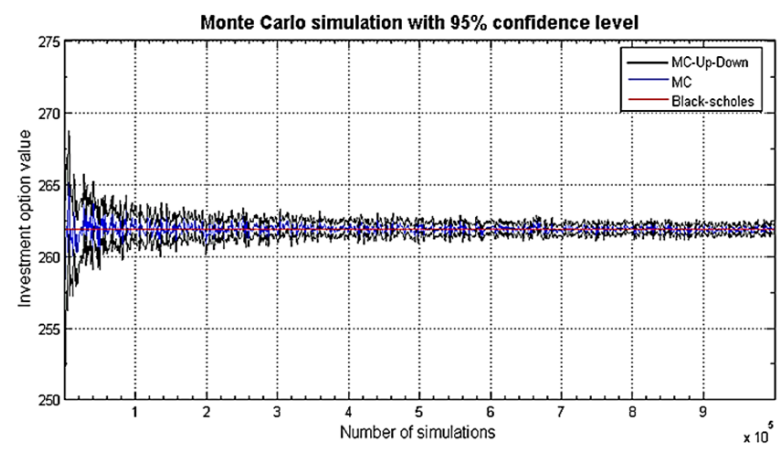

Figure 8. The value of the investment option (blue) and the $95 \%$ confidence level with a MC simulation in comparison to the analytical solution(red).

\section{Finite difference method}

Finally, Following [9], we solve the investment option case with FDM. We derive a numerical solution with the explicit and implicit interpolation scheme. In addition to the parameters listed in the Table 2, we have to set additional parameters for the grid. Limiting the domain to $X=900$ with $N=250$ nodes and using $M=10^{5}$ time steps, we obtain:

$$
\begin{aligned}
V_{F D M, \exp } & =264.7458, \\
V_{F D M, i m p} & =264.7362 .
\end{aligned}
$$

Comparing the values to the exact solution, we note that the values are very close to the exact solution with both methods. Moreover, we note that the investment is valuated naturally in the whole domain with FDM, which is not possible for example with the MC method due to path independence. Corresponding error plot of the values in log-log scale is given in Figure 9. 


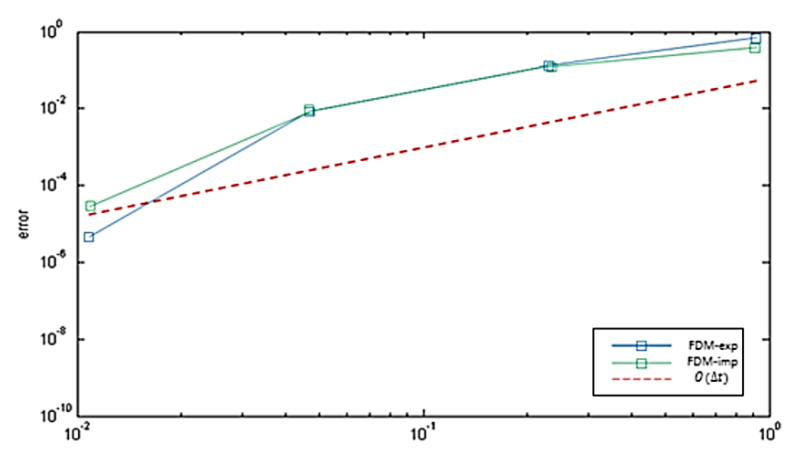

Figure 9. Absolute error for the explicit and implicit FDM.

\subsection{Discussion of Results}

Using the accuracy of the numerical solution as only metric is problematic since by increasing the number of iterations by one step does not equal increased the grid size by one node. Comparison of the numerical methods for the investment case with respect to fixed absolute error and wall-clock time in seconds is presented in Table 3.

Table 3. Comparison of the numerical methods

\begin{tabular}{|c|c|c|c|c|}
\hline & MC & FDM-Exp & FDM-Imp & L3C2M \\
\hline Inputs & $100 \cdot 10^{6}$ & $(80,9000)$ & $(80,9000)$ & $(5000,172)$ \\
Value $(V)$ & 264.8050 & 264.7458 & 264.7362 & 264.7611 \\
Clock time & 48.2573 & 0.7747 & 0.6002 & 0.0695 \\
Error $\left(\frac{V_{\text {Num. }}-V_{\text {exact }}}{V_{\text {exact }}}\right)$ & 0.00024165 & 0.00001804 & 0.00001804 & 0.0000132 \\
\hline
\end{tabular}

From Table 3, we conclude that: In general, each of the three numerical methods has the values are very close to the exact solution. Although the MC method works very well for pricing European option, approximates every arbitrary exotic option, flexible in handling varying, and even higher dimensional financial problems, the convergence of MC method is very slow and take a long run-time compared to other methods. FDM converges faster than MC method and more accurate, they are fairly robust and good for pricing options where there are possibilities of early exercise, but FDM has become uncommonly used today -particularly amongst practitioners-due to the required mathematical sophistication; these too cannot readily be used for high-dimensional problems, and also very complicated in implementation. Finally, we can see that, L3C2M method outperforms all the other methods in efficiency, and convergence faster another way and considers simple in implementation compared to other ways of the case study with given parameters.

\section{Conclusions}

In this paper, we address the real option valuation of an uncertainty investment in a solar power plant project and the optimal time to invest under the support programme of Egypt: a feed-in-tariff, electricity price and transitory subsidy. Three sources of uncertainty are considered: the electricity price, the level of solar generation and feed-in tariff. We construct new general numerical method, lobatto3C-Milstein (L3CM) method, to use in stochastic process of real option valuation, when the analytic solutions are lacking. Our real option framework differs of a previous work since, the new numerical methods L3CM method is integrated with option theory and the four economic elements cost, value, risk and flexibility to value a real option. We examine L3CM method with commonly used two methods, finite difference methods (FDM) and Monte Carlo (MC) method in an option valuation for investment with uncertainty in a case study. 
Acknowledgments: The authors thanks the anonymous referees for careful reading and many helpful suggestions to improve the presentation of this paper. This research was partly financed by NSFC grant 71350005 and 91646106. Additionally, this work is supported by Higher Education Commission of Egypt.

Author Contributions: MA. Eissa carried out the numerical method for SDEs, the numerical solution of the valuation problems and relatively more involved in Matlab. B. Tian dealt more with conception, theoretical issues and analysis of the results. All authors read and approved the final manuscript.

Conflicts of Interest: The authors declare that they have no competing interests.

\section{Appendix A. Background of Lobatto3C methods}

The fundamental analysis contain convergence and stability for numerical methods for differential equations are provided in [35,53-55]. The families of RK methods based on Lobatto quadrature formulas are one of several classes of fully implicit RK methods possessing good stability properties for ODEs. The number 3 is usually found in the literature associated to Lobatto methods. Ehle [56] introduced Lobatto 3A, 3B and 3C classes. The general definition of the Lobatto3C methods were due to $[57,58]$. For more information about the fundamental properties of Lobatto methods, we recommend [35,53].

The classes of s-stage Lobatto methods are given in [35]

$$
\begin{aligned}
Y_{n i} & =y_{n}+h \sum_{j=1}^{s} a_{i j} f\left(t_{n}+c_{j} h, Y_{n j}\right), \quad i=1,2, \ldots, s, \\
y_{n+1} & =y_{n}+h \sum_{j=1}^{s} b_{j} f\left(t_{n}+c_{j} h, Y_{n j}\right),
\end{aligned}
$$

where the stage value $s$ satisfies $s \geq 2$ and the coefficients $a_{i j}, b_{j}$ and $c_{j}$ characterized the Lobatto methods. The $s$ intermediate values $Y_{n j}$ for $j=1, \ldots, s$ are called the internal stages and can be considered as approximations to the solution at $t_{n}+c_{j} h$. The main numerical approximation at $t_{n+1}=t_{n}+h$ is given by $y_{n+1}$. Lobatto methods are characterized by $c_{1}=0$ and $c_{s}=1$. For a fixed value of $s$ the various families of Lobatto methods share the same coefficients $b_{j}$ and $c_{j}$. In addition, the coefficients $a_{i j}$ are vary depending on the classes of Lobatto methods. For Lobatto3C class, the $a_{i j}$ defined as

$$
a_{i 1}=b_{1}, \quad i=1, \ldots, s,
$$

and determined the remaining $a_{i j}$ by $C(s-1)$. The coefficients of the Lobatto3C methods can be

\begin{tabular}{|c|c|c|c|c|c|c|}
\hline \multirow[b]{2}{*}{0} & \multirow[b]{2}{*}{$\frac{1}{2}$} & \multirow[b]{2}{*}{$-\frac{1}{2}$} & 0 & \multicolumn{2}{|c|}{$\begin{array}{ll}\frac{1}{6} & -\frac{1}{3}\end{array}$} & $\frac{1}{6}$ \\
\hline & & & 1 & . & 5 & 1 \\
\hline 1 & $\frac{1}{2}$ & $\frac{1}{2}$ & $\overline{2}$ & $\overline{6}$ & 12 & $-\frac{1}{12}$ \\
\hline & & & 1 & $\frac{1}{2}$ & $\frac{2}{3}$ & $\frac{1}{2}$ \\
\hline & 2 & 2 & & $\frac{1}{2}$ & $\frac{2}{3}$ & $\frac{1}{2}$ \\
\hline
\end{tabular}
displayed by the Butcher-tabelau in Table 4 .

Table 4. The Lobatto3C methods of orders 2 (left) and order 4 (right)

The stability properties of numerical methods for deterministic ODEs are reported in [35]. In the following, we present the well-known results for Lobatto methods in a way that helps to motivate the SDEs analysis.

Proposition 1. (See [35]) The s-stage Lobatto3C methods (9-10) applied to the scalar test equation

$$
\mathrm{d} X(t)=\lambda X(t) \mathrm{d} t, \quad t>0, \quad X(0)=X_{0} \neq 0,
$$


where $\lambda \in \mathbb{C}$ is a constant, yields

$$
y_{n+1}=R(\lambda, h) y_{n}
$$

with

$$
R(Z)=1+Z b^{T}(I-Z A)^{-1} \mathbf{1},
$$

where $b^{T}=\left(b_{1}, \ldots, b_{s}\right), A=\left(a_{i j}\right)_{i, j=1}^{s}, \mathbf{1}=(1, \ldots, 1)^{T}$, and $I$ is the identity matrix. $R(Z)$ is called the stability function of the numerical method, which can be written for implicit methods as rational function with numerator and demonstrator of degree $\leq s$ as follows

$$
R(Z)=\frac{P(Z)}{Q(Z)}, \quad \operatorname{deg} P=k, \quad \operatorname{deg} Q=j .
$$

Let $S_{L}$ is the stability domain for the Lobatto3C methods (9-10), Then the method with stability function (15) is A-stable if and only if $|R(i y)| \leq 1$ for all real $y$ and $R(Z)$ is analytic for $R e Z<0$. In addition, using the definition of the method coefficients (11), and (proposition 3.8 in [35]), we find that the method also is L-stable. Furthermore, the Lobatto3C methods are characterized by non-stiff order $(2 s-2)$, not symmetric, algebraically stable, B-stable, and the stability function $R(z)$ is given by $(s-2, s)$ Padé approximation to $e^{z}$. So, the the Lobatto3C methods (9-10) are described as excellent methods for stiff problems.

\section{References}

1. WWF (World Wildlife Fund) The Energy Report - 100\% Renewable Energy by 2050. Gland, Switzerland (2011).

2. IEO (International Energy Outlook) 2016. Avilable: http://www.eia.gov/forecasts/ieo/.

3. Andersson, B.A.; Azar, C.; Holmberg, J.; Karlsson, S. Material constraints for thin-film solar cells. Energy 1998, 23, 407-411.

4. Parida, B.; Iniyan, S.; Goic, R. A review of solar photovoltaic technologies. Renewable and sustainable energy reviews 2011, 15, 1625-1636.

5. EIA (2016) Updated Capital Cost Estimates for Electricity Generation Plants Available: www.eia.gov/forecasts/ ieo/pdf/0484(2016).pdf.

6. Wiser, R.; Bolinger, M.; Barbose, G. Using the federal production tax credit to build a durable market for wind power in the United States. The Electricity Journal 2007, 20, 77-88.

7. Fagiani, R.; Barquín, J.; Hakvoort, R. Risk-based assessment of the cost-efficiency and the effectivity of renewable energy support schemes: Certificate markets versus feed-in tariffs. Energy policy 2013, 55, 648-661.

8. Daim, T.U.; Amer, M.; Brenden, R. Technology roadmapping for wind energy: case of the Pacific Northwest. Journal of Cleaner Production 2012, 20, 27-37.

9. Sorsimo, A. Numerical Methods in Real Option Analysis. Master's thesis, Department of Economics Aalto University School of Business, 2015.

10. Toke, D. Renewable financial support systems and cost-effectiveness. Journal of Cleaner Production 2007, 15, 280-287.

11. Dixit, A.K.; Pindyck, R.S. Investment under uncertainty; Princeton university press, 1994.

12. Graham, J.R.; Harvey, C.R. The theory and practice of corporate finance: Evidence from the field. Journal of financial economics 2001, 60, 187-243.

13. Graham, J.; Harvey, C. How do CFOs make capital budgeting and capital structure decisions? Journal of applied corporate finance 2002, 15, 8-23.

14. Fernandes, B.; Cunha, J.; Ferreira, P. The use of real options approach in energy sector investments. Renewable and Sustainable Energy Reviews 2011, 15, 4491-4497.

15. Abadie, L.M.; Chamorro, J.M. Valuation of wind energy projects: A real options approach. Energies 2014, 7, 3218-3255.

16. Gazheli, A.; Di Corato, L. Land-use change and solar energy production: a real option approach. Agricultural Finance Review 2013, 73, 507-525. 
17. Platen, P.E.K.E. Numerical solution of stochastic differential equations. Applications of Mathematics Series 1999, 23.

18. Kloeden, P.E.; Platen, E. Higher-order implicit strong numerical schemes for stochastic differential equations. Journal of statistical physics 1992, 66, 283-314.

19. Higham, D.J.; Mao, X.; Stuart, A.M. Strong convergence of Euler-type methods for nonlinear stochastic differential equations. SIAM Journal on Numerical Analysis 2002, 40, 1041-1063.

20. Ding, X.; Ma, Q.; Zhang, L. Convergence and stability of the split-step $\theta$-method for stochastic differential equations. Computers $\mathcal{E}$ Mathematics with Applications 2010, 60, 1310-1321.

21. Huang, C. Exponential mean square stability of numerical methods for systems of stochastic differential equations. Journal of Computational and Applied Mathematics 2012, 236, 4016-4026.

22. Wang, P.; Liu, Z. Split-step backward balanced Milstein methods for stiff stochastic systems. Applied Numerical Mathematics 2009, 59, 1198-1213.

23. Guo, Q.; Li, H.; Zhu, Y. The improved split-step $\theta$ methods for stochastic differential equation. Mathematical Methods in the Applied Sciences 2014, 37, 2245-2256.

24. Voss, D.A.; Khaliq, A.Q. Split-step Adams-Moulton Milstein methods for systems of stiff stochastic differential equations. International Journal of Computer Mathematics 2015, 92, 995-1011.

25. B. Tian, M. A. Eissa, S.Z. Two Families of Theta Milstein Methods in A Real Options Framework. (CMCGS 2016) 5th Annual International Conference on Computational Mathematics, Computational Geometry and Statistics, Singapore, 18-19 January 2016. DOI : 10.5176/2251 - 1911CMCGS16.3, 2015.

26. J. Weston, T. Copeland, K.S. Financial Theory and Corporate Policy, fourth edition ed.; New York, Pearson Addison Wesley, 2005.

27. Black, F.; Scholes, M. The pricing of options and corporate liabilities. The journal of political economy 1973, pp. 637-654.

28. Merton, R.C. Theory of rational option pricing. The Bell Journal of economics and management science 1973, pp. 141-183.

29. Brennan, M.J.; Schwartz, E.S. Finite difference methods and jump processes arising in the pricing of contingent claims: A synthesis. Journal of Financial and Quantitative Analysis 1978, 13, 461-474.

30. Boyle, P.P. Options: A monte carlo approach. Journal of financial economics 1977, 4, 323-338.

31. Fadugba, S.; Nwozo, C.; Babalola, T. The comparative study of finite difference method and Monte Carlo method for pricing European option. Mathematical Theory and Modeling 2012, 2, 60-66.

32. Pringles, R.; Olsina, F.; Garcés, F. Real option valuation of power transmission investments by stochastic simulation. Energy Economics 2015, 47, 215-226.

33. Thompson, M.; Barr, D. Cut-off grade: A real options analysis. Resources Policy 2014, 42, 83-92.

34. Sauer, T. Numerical Analysis; Pearson, 2005.

35. E. Hairer, G.W. Solving ordinary differential equations II: Stiff and differential-algebraic problems; Springer, Berlin, 1996.

36. Global trends in renewable energy investment 2016, Frankfurt School UNEP Collaborating Centre for Climate and Sustainable Energy Finance (2016). Avilable: http://fs-unep-centre.org/publications/ global-trends-renewable-energy-investment-2016.

37. Hirth, L. The market value of variable renewables: The effect of solar wind power variability on their relative price. Energy economics 2013, 38, 218-236.

38. Scorah, H.; Sopinka, A.; van Kooten, G.C. The economics of storage, transmission and drought: integrating variable wind power into spatially separated electricity grids. Energy Economics 2012, 34, 536-541.

39. Gross, R.; Blyth, W.; Heptonstall, P. Risks, revenues and investment in electricity generation: Why policy needs to look beyond costs. Energy Economics 2010, 32, 796-804.

40. Egypt in Transition: Infrastructure and Development, British Expertise Available: http://www.britishexpertise.org/ bx/upload/Events/Egyptintransition_Spring2015_LR.pdf, 2015.

41. EEHC (Egyptian Electricity Holding Company)). Annual report for FY 2012/2013.

42. New and Renewable Energy Authority (NREA), Annual Report 2012/2013, Available http://nrea.gov.eg/annual\% 20report/Annual_Report_2012_2013_eng.pdf.

43. Amereller, Investing in Renewable Energy in Egypt, January 2015. Available http://amereller.de/fileadmin/PDFs/ ALC_Investing-in-Renewable-Energies-Jan-2015.pdf. 
44. New and Renewable Energy Authority (NREA) http://nrea.gov.eg/beta/Investors/Legislation.

45. Min, K.J.; Lou, C.; Wang, C.H. An exit and entry study of renewable power producers: A real options approach. The Engineering Economist 2012, 57, 55-75.

46. Mahmoud A. Eissa, Yu Xiao, Z.Y. Lobatto3C-Milstein methods for stiff stochastic differential equations. Underreview.

47. Schulmerich, M. Real options valuation: the importance of interest rate modelling in theory and practice; Springer Science \& Business Media, 2010.

48. Wang, T. Analysis of Real Options in Hydropower Construction Projects-A Case Study in China. PhD thesis, Massachusetts Institute of Technology, 2003.

49. The central bank of Egypt, http://www.cbe.org.eg/English/Statistics/, http://www.tradingeconomics.com/egypt/ interest-rate.

50. New and Renewable Energy Authority (NREA), Annual Report 2009/2010, Available http://nrea.gov.eg/annual\% 20report/annual2010En.pdf.

51. Stern, N., Real Option; chapter 8, pp. 1-50.

52. Egypt's information portal Available: http://www.eip.gov.eg/Documents/StudiesDetails.aspx?id=2142.

53. E. Hairer, S. P. Nørsett, G.W. Solving ordinary differential equations I: Nonstiff problems; Springer, Berlin, 1993.

54. Ramadan, M.; ElDanaf, T.S.; Eissa, M.A. System of Ordinary Differential Equations Solving Using Cellular Neural Networks. Journal of Advanced Mathematics and Applications 2014, 3, 182-194.

55. Ramadan, M.; ElDanaf, T.S.; Eissa, M.A. Approximate Solutions of Partial Differential Equations using Cellular Neural Networks. International Journal of Science and Engineering Investigations 2015, 4, 14-21.

56. Ehle, B.L. ON PADE APPROXIMATIONS TO THE EXPONENTIAL FUNCTION AND A-STABLE METHODS FOR THE NUMERICAL SOLUTION OF INITIAL VALUE PROBLEMS. PhD thesis, University of Waterloo, 1969.

57. Axelsson, O. A note on a class of stronglyA-stable methods. BIT Numerical Mathematics 1972, 12, 1-4.

58. Chipman, F. A-stable Runge-Kutta processes. BIT Numerical Mathematics 1971, 11, 384-388.

(C) 2017 by the authors; licensee Preprints, Basel, Switzerland. This article is an open access article distributed under the terms and conditions of the Creative Commons Attribution (CC-BY) license (http://creativecommons.org/licenses/by/4.0/). 